Débora Miriam Raab Glina ${ }^{1}$

Lis Andreia Soboll ${ }^{2}$

\section{Intervenções em assédio moral no trabalho: uma revisão da literatura}

\author{
Bullying at work interventions: a literature review
}

1 Psicóloga, Doutora em Psicologia Social, professora colaboradora no curso de especialização em Medicina do Trabalho, Faculdade de Medicina, Universidade de São Paulo, São Paulo, SP, Brasil.

2 Psicóloga, Doutora em Medicina, Docente na Universidade Federal do Paraná, Departamento de Psicologia, e na FAE Centro Universitário Franciscano, no Programa de Mestrado em Organizações e Desenvolvimento, Curitiba, PR, Brasil.

Contato:

Débora Miriam Raab Glina

E-mail:

deboraglina@uol.com.br

O trabalho não foi subvencionado, não há conflito de interesses e não é baseado em tese.

O trabalho foi parcialmente apresentado como pôster (PS 34) no $30^{\circ}$ Congresso Internacional em Saúde Ocupacional (ICOH), em Cancun, México, em 2012.

\section{Resumo}

Justificativa: Embora a problemática do assédio moral no trabalho venha sendo estudada há mais de três décadas, aspectos de gerenciamento e prevenção ainda necessitam de maior estudo e sistematização. Objetivo: Identificar e sistematizar os métodos de intervenção em assédio moral. Método: Pesquisa bibliográfica sobre o tema em bases de dados (Medline, Psychinfo, SciELO e Lilacs), livros, teses e sites especializados (1980 a 2010). Resultados e discussão: O conceito de assédio moral no trabalho é inicialmente delimitado, explicitando os elementos caracterizadores básicos. As intervenções são organizadas em níveis de prevenção (primária, secundária e terciária) e alvos das ações: indivíduos diretamente envolvidos, testemunhas, grupo de trabalho e organização. Os aspectos que levam ao sucesso das intervenções e às boas práticas são elencados. Conclusão: Dada a natureza complexa do assédio moral no trabalho, intervenções isoladas e pontuais não funcionam. A abordagem precisa ser abrangente e o acompanhamento das ações, sistemático. Cada caso é singular e o desenho da intervenção deve considerar o contexto organizacional e envolver os vários atores sociais.

Palavras-chave: assédio moral no trabalho; prevenção; intervenção.

\begin{abstract}
Although the phenomenon of bullying at work has been studied for more than three decades, management and prevention aspects still require greater study and systematization. Objective: to identify and systematize intervention methods on bullying. Method: bibliographical research was conducted on this topic in databases (Medline, Psychinfo, SciELO, Lilacs), books, theses and specialized sites (from 1980 to 2010). Results and discussion: the concept of bullying at work was circumscribed making the basic elements that characterize it explicit. Interventions are organized by levels of prevention (primary, secondary and tertiary) and intervention goals: targets of bullying, witnesses, workgroups and organizations. Aspects that lead to the success of the interventions and good practices are listed. Conclusion: given the complex nature of bullying at work, isolated and one-off interventions do not work. The approach needs to be comprehensive and the monitoring of actions systematic. Each case is unique and intervention design should acknowledge the organizational context and involve all the stakeholders.
\end{abstract}

Keywords: bullying at work; prevention; intervention. 


\section{Introdução}

Comportamentos hostis, repetitivos e prolongados no contexto de trabalho são características centrais do que se tem denominado assédio moral, tema bastante explorado na literatura estrangeira desde a década de 1980 (LEYMANN, 1996). Esta problemática também é abordada em pesquisas brasileiras desde os anos 2000. Entretanto, ainda são poucas as referências sobre o processo de intervenção nestes casos, embora no cotidiano organizacional observe-se a busca por soluções, tanto visando ao enfrentamento, como a prevenção. Para Einarsen (2000), embora tenha ocorrido uma proliferação de pesquisas na Europa desde a década de 1980, em 2000 o campo do assédio moral no trabalho ainda se encontrava na sua infância, especialmente no que se refere aos procedimentos de enfrentamento e gerenciamento. Segundo o mesmo autor, alguns programas de prevenção e intervenção foram descritos na literatura (ADAMS; BRAY, 1992; EINARSEN; RAKNES; MATTHIESEN, 1994; KAYE, 1994; LEYMANN, 1990, 1991, 1992; RESCH; SCHUBINSKI, 1996), mas nenhum deles se baseou em um modelo teórico bem fundamentado e testado. Mesmo considerando as evoluções em relação ao conceito e aos instrumentos diagnósticos do assédio moral, os relatos de intervenções são escassos e não há suficientes estudos de avaliação formal dos resultados e da eficácia destas intervenções (BESWICK; GORE; PALFERMAN, 2006). No Brasil, especialmente, as intervenções voltadas ao tratamento ou à prevenção das situações de assédio moral são incipientes.

Não menos importante é o fato, consensualmente estabelecido na literatura internacional, de que o assédio moral no trabalho vem crescendo no mundo todo, na esteira das transformações e das pressões no mundo do trabalho (SHEEHAN, 2004).

Além dos danos que pode trazer ao indivíduo assediado e aos colegas de trabalho (testemunhas), há um reconhecimento de que o assédio moral e a violência no trabalho são nocivos à funcionalidade do local de trabalho (DI MARTINO, 2002). Este panorama torna necessário e premente que se encontrem formas de prevenção e gerenciamento destes casos.

Com o propósito de sistematizar as práticas de gerenciamento e prevenção do assédio moral, este artigo apresenta uma revisão da literatura nacional e internacional sobre o tema.
Para tanto, contempla-se brevemente o conceito de assédio moral no trabalho para então abordar as intervenções em termos de níveis de prevenção e dos alvos das ações. A revisão sintetiza ainda os achados em relação aos aspectos que levam ao sucesso das intervenções e às boas práticas.

\section{Procedimentos metodológicos}

O estudo realizado se apresenta como uma pesquisa bibliográfica cujo escopo foi limitado às intervenções voltadas ao assédio moral no trabalho. Foram consultadas as seguintes bases de dados: Medline, Psychinfo, SciELO e Lilacs (de 1980 a 2010). Os termos-chave utilizados foram: assédio moral no trabalho, bullying, mobbing, emotional abuse, victimization, harassment, bosing, acosso moral, psychological violence, violência psicológica. Esses termos foram cruzados com as palavras-chave prevenção, intervenção, prevention, intervention, assessment. Os idiomas foram limitados ao português, espanhol, inglês e francês. Na consulta às bases de dados, foram utilizados os requisitos referentes à descrição de medidas de intervenção. Foram incluídos apenas os textos que descreviam intervenções e enfocassem formas de prevenção.

Os anais de conferências e congressos sobre violência e assédio moral foram também pesquisados, assim como capítulos de livros, dissertações e teses disponibilizados na internet e obtidos através das buscas no Google, Google Acadêmico e no site sobre assédio moral. ${ }^{3}$ Os sites da Organização Mundial da Saúde, da Organização Internacional do Trabalho, da Agência Europeia de Segurança e Saúde no Trabalho e o site dos pesquisadores Leymann e Einarsen foram visitados em busca de relatórios científicos e artigos. Nos sites de busca Google e Google Acadêmico, pesquisou-se variando as palavras-chave e o idioma. As palavras-chave foram as mesmas utilizadas nas bases bibliográficas anteriormente citadas.

Dado que a estratégia de busca poderia capturar estudos não relevantes, foram planejados passos subsequentes no processo de revisão para identificar e omitir estes estudos. A primeira seleção se deu através da leitura de títulos e resumos. Os artigos completos só foram obtidos para os estudos que atendessem os requisitos estabelecidos e apresentassem boa qualidade. Foram priorizados os artigos de periódicos que passam por análise de revisores (peer reviewed) e aqueles provenientes de fontes reconhecidamente confiáveis.

De aproximadamente 250 documentos inicialmente triados (por título e resumo), permaneceram 98 documentos.

${ }^{3}$ No link: www.assediomoral.org 


\section{Resultados e discussão}

\section{O que é assédio moral no trabalho e quais os aspectos que o definem}

O assédio moral no trabalho refere-se a um padrão relacional entre as pessoas no contexto de trabalho. Existem inúmeras definições, cada uma enfatizando determinados aspectos. Entende-se, para este estudo, o assédio moral como aparecendo na forma cronificada de comportamentos hostis e rudes em:

[...] um processo grave e extremo de violência psicológica, que acontece de maneira continuada e repetitiva no contexto de trabalho e que produz efeito de humilhação, ofensa e constrangimento. (SOBOLL, 2010, p. 40)

A terminologia utilizada também varia (harassment, mobbing, bullying, acosso moral, petty tyranny entre outros), com algumas diferenças conceituais entre os termos. Para efeitos deste artigo, as diferentes terminologias foram utilizadas como sinônimos e uniformizadas sob o termo assédio moral no trabalho.

Os principais critérios encontrados nas várias definições e que têm sido utilizados para afirmar que uma determinada situação configura o assédio moral no trabalho são: comportamento hostil, aspectos temporais, o assédio como um processo com fases de progressiva gravidade (processo em escalação, efeitos na saúde, diferença de poder e intencionalidade). Esses aspectos definidores são tratados no Quadro 1.

Predomina entre os autores pesquisados a consideração do assédio moral no trabalho como um comportamento, qualificando-o de forma negativa. Para deixar claro que não se trata de algo eventual, esporádico, é de consenso entre os autores tratar-se de uma prática recorrente e persistente. Para Leymann e Gustafsson (1996), é a dimensão temporal, isto é, a duração e a frequência que caracterizam a agressão sistemática e de longo prazo. Entretanto, não há consenso entre os autores consultados em relação a qual frequência e duração considerar, podendo ser desde um único ato negativo até ter uma incidência semanal. Igualmente, a duração é variável entre os autores consultados, mas predomina como critério a duração superior a 6 meses.

O assédio moral é visto como tendo potencial para causar efeitos danosos e até devastadores na pessoa-alvo, sendo mencionados vários tipos de danos, físicos e psicológicos.

Há autores, por exemplo, Salin (2003), que afirmam que o assediado percebe-se sem condições de se defender. $\mathrm{O}$ assédio moral é considerado por vários autores como um processo - e não um acontecimento pontual - composto por diferentes tipos de comportamentos com tendência à evolução e ao agravamento (DAVENPORT; SWARTZ; ELLIOTT, 1999; LEYMANN, 1996; RESCH; SCHUBINSKI, 1996).
Sendo um processo quando o objetivo é a prevenção ou a intervenção precoce, é importante a compreensão de como e quando ele se origina, .

A intencionalidade é mencionada em várias definições, seja a intenção de excluir do trabalho, de levar a pedir demissão ou outras. Para Einarsen e Mikkelsen (2003), a intencionalidade pode ou não estar presente, ou seja, o indivíduo pode sentir-se assediado mesmo quando o assediador não tem intenção de assediá-lo. Assim como Rayner, Hoel e Cooper (2002), entendemos que a intencionalidade, como tal, não pode ser considerada como um elemento essencial para a identificação do assédio moral, visto que pode existir ou não e há dificuldade na sua comprovação.

\section{Intervenções voltadas ao assédio moral no trabalho}

Zapf e Gross (2001) consideram que o assédio moral pode ser visto ou como uma forma severa de estresse no trabalho, ou como um conflito social não resolvido que aumentou muito com crescente disparidade de forças. Ele é considerado um estressor social severo (ZAPF; EINARSEN, 2005). Nesse sentido, o assédio moral no trabalho pode ser considerado um importante risco psicossocial e, portanto, deveria ser tratado da mesma maneira que os demais riscos (EUROPEAN AGENCY FOR SAFETY AND HEALTH AT WORK, 2009). Sua avaliação (risk assessment) envolve os mesmos princípios e processos básicos aplicáveis a outros riscos presentes no local de trabalho. Dentro da mesma linha de raciocínio, Leka e Cox (2008) apresentam um modelo para gerenciamento do risco psicossocial composto das seguintes fases:

- Avaliação de riscos e auditoria das práticas existentes: uma avaliação de riscos é um exame cuidadoso do que pode causar danos às pessoas no local de trabalho. Ele envolve identificar e avaliar a extensão dos riscos, considerando as precauções existentes. Assim, os empregadores deveriam estabelecer se existe violência, agressão ou assédio no trabalho ou se existe potencial para a sua ocorrência e identificar as situações em que os trabalhadores podem sofrer dano físico ou mental em decorrência da violência ou do assédio moral no trabalho.

- Desenvolvimento de planos de ação: depois de completar a avaliação de riscos, devem ser desenvolvidas listas das medidas preventivas necessárias em ordem de prioridade, destacando quem é responsável e o prazo.

- Implementação do plano para redução dos riscos ou intervenções: envolvendo os trabalhadores e seus representantes no processo.

- Avaliação regular do plano de ação.

- Aprendizagem organizacional, visando à atualização e às adaptações do plano de ação. 
Quadro 1 Aspectos definidores do assédio moral no trabalho a partir da literatura consultada

\begin{tabular}{|c|c|c|}
\hline Aspecto & Qualificadores & Autores (exemplos) \\
\hline \multirow{4}{*}{$\begin{array}{l}\text { Assédio moral enquanto compor- } \\
\text { tamento }\end{array}$} & Conduta abusiva & $\begin{array}{l}\text { Unison (2003 apud DI MARTINO; } \\
\text { HOEL; COOPER, 2003) } \\
\text { Hirigoyen (2001). }\end{array}$ \\
\hline & Ato negativo & $\begin{array}{l}\text { Vartia (1991). } \\
\text { Einarsen (2000). }\end{array}$ \\
\hline & Tentativas persistentes & Brodsky (1976). \\
\hline & Comportamento hostil & Leymann (1996). \\
\hline \multirow{3}{*}{ Temporal: frequência } & Recorrente (sem precisar números) & $\begin{array}{l}\text { Vartia (1991). } \\
\text { Hirigoyen (2002). } \\
\text { Einarsen et al. (2003). }\end{array}$ \\
\hline & $\begin{array}{l}\text { De vez em quando ou semanal- } \\
\text { mente }\end{array}$ & $\begin{array}{l}\text { Einarsen; Skogstad (1996). } \\
\text { Leymann (1990). }\end{array}$ \\
\hline & $\begin{array}{l}\text { Um único ato negativo (em certas } \\
\text { circunstâncias) }\end{array}$ & $\begin{array}{l}\text { Einarsen et al. (2003). } \\
\text { Hoel; Cooper (2000). } \\
\text { Zapf (1999). }\end{array}$ \\
\hline \multirow{5}{*}{ Temporal: duração } & $\begin{array}{l}\text { Prolongada, mas um período } \\
\text { predefinido }\end{array}$ & $\begin{array}{l}\text { Vartia (1991). } \\
\text { Hirigoyen (2002). } \\
\text { Einarsen et al. (2003). }\end{array}$ \\
\hline & Pelo menos seis meses & $\begin{array}{l}\text { Niedl (1996). } \\
\text { O’Moore et al. (2003). }\end{array}$ \\
\hline & Últimos seis meses & $\begin{array}{l}\text { Björqvist et al. (1994). } \\
\text { Einarsen; Skogstad (1996). }\end{array}$ \\
\hline & Pelo menos 12 meses & Leymann (1996). \\
\hline & Acima de 15 meses & Zapf (1999). \\
\hline \multirow{8}{*}{ Efeitos na saúde } & Menos energia e vitalidade & Vaez et al. (2004). \\
\hline & $\begin{array}{l}\text { Tensões musculares, impossibili- } \\
\text { dade de descansar, palpitações e } \\
\text { tontura }\end{array}$ & Davenport et al. (1999). \\
\hline & $\begin{array}{l}\text { Problemas psicossomáticos e } \\
\text { doenças físicas }\end{array}$ & $\begin{array}{l}\text { Einarsen e Raknes (1995). } \\
\text { Niedl (1995). } \\
\text { Zapf et al. (1996). }\end{array}$ \\
\hline & $\begin{array}{l}\text { Aumento no nível de estresse do } \\
\text { indivíduo }\end{array}$ & Mikkelsen; Einarsen (2001). \\
\hline & Ansiedade e depressão & Di Martino et al. (2003). \\
\hline & $\begin{array}{l}\text { Comportamentos heteroagressivos } \\
\text { e autoagressivos }\end{array}$ & Nidle (1996). \\
\hline & $\begin{array}{l}\text { Ansiedade e transtorno do estresse } \\
\text { pós-traumático }\end{array}$ & Leymann; Gustafsson (1996). \\
\hline & $\begin{array}{l}\text { Incapacidade para o trabalho e } \\
\text { suicídio }\end{array}$ & Groeblingshoff; Becker (1996). \\
\hline $\begin{array}{l}\text { Assediado se percebe sem con- } \\
\text { dições de se defender }\end{array}$ & & $\begin{array}{l}\text { Einarsen (1999). } \\
\text { Hoel; Cooper (2000). } \\
\text { Salin (2003). }\end{array}$ \\
\hline $\begin{array}{l}\text { Processo: composto de fases de pro- } \\
\text { gressiva gravidade (em escalação) }\end{array}$ & & Leymann (1996). \\
\hline Intencionalidade & & $\begin{array}{l}\text { Leymann (1996). } \\
\text { Freitas et al. (2008). }\end{array}$ \\
\hline
\end{tabular}

Fontes: conteúdo elaborado pelas autoras com base nos estudos mencionados na coluna "Autores (exemplos)" 


\section{Prevenção de violência e assédio moral no trabalho}

Spurgeon (2003) afirma que as medidas de prevenção do assédio moral no trabalho têm probabilidade de ocorrer em paralelo com aquelas para riscos psicossociais, como o estresse no trabalho. Segundo este mesmo autor, ao selecionar uma medida, é essencial saber em que fase está o processo de assédio moral, uma vez que há diferentes medidas para prevenir o seu desenvolvimento, pará-lo ou reabilitar as vítimas.

Existem três enfoques básicos: a prevenção primária, a secundária e a terciária (LEKA; COX, 2008). As intervenções primárias são proativas por natureza, visando à redução dos riscos. Elas incluem, por exemplo, políticas e planos de ação antiassédio moral, registro de incidentes violentos e um replanejamento do ambiente psicossocial de trabalho. As intervenções secundárias (reações oportunas) visam aumentar os recursos individuais. Incluem, por exemplo: treinamento, inquérito dos trabalhadores e resolução de casos de conflito. As intervenções terciárias têm por alvo a redução e a cura dos danos causados pelo assédio moral e a violência. Incluem, entre outros, acordos corporativos, aconselhamento e terapia.

\section{Aspectos-chave das intervenções}

Tendo em vista que o assédio moral e a violência no trabalho são fenômenos multidimensionais, a prevenção/intervenção deveria ter um enfoque mais amplo, incluindo o indivíduo, o trabalho, atividades em nível organizacional e social. Assim, a melhor resposta seria mais buscar as causas do que os efeitos do assédio moral e da violência no trabalho. Ao invés de buscar uma solução única, adequada a qualquer situação ou problema, a gama completa de causas que geram o assédio moral e a violência no trabalho deveria ser analisada e uma variedade de estratégias de intervenção adotada (DI MARTINO, 2002).

Para a prevenção e a administração efetiva das situações de violência psicológica nas relações de trabalho, as intervenções devem ser direcionadas tanto para os indivíduos, quanto para a estrutura organizacional (CHAPPELL; DI MARTINO, 2006). A base do gerenciamento do assédio moral e da violência no trabalho é a tolerância zero para todos os tipos de violência, física ou psicológica, provenientes de fora ou de dentro do local de trabalho (LEKA; COX, 2008).

A European Agency for Safety and Health at Work (2002a) e DeFrank e Cooper (1987) afirmam que as intervenções deveriam ser classificadas de acordo com o nível, isto é, nível do indivíduo, nível da interface indivíduo x organização e nível organizacional e foco das ações, ou seja, prevenção, reação e reabilitação/medidas corretivas.
As intervenções pesquisadas na literatura científica serão apresentadas de acordo com o nível, sendo: nível 1: indivíduos envolvidos diretamente - assediado(s) e assediador(es); nível 2: grupo, equipe e colegas (interface indivíduo/organização); nível 3: organizações.

\section{Intervenções de nível 1: para indivíduos envolvidos diretamente - assediado(s) e assediador(es)}

Segundo a European Agency for Safety and Health at Work (2002a), as intervenções em nível individual visam aumentar os recursos do indivíduo para lidar com o estresse.

Para as vítimas do assédio moral no trabalho: aconselhamento, grupo de apoio, estratégias de reabilitação e retorno ao trabalho, ouvidoria. Tehrani (2003) sugere utilizar conselheiros profissionalmente treinados. Dentre as técnicas citadas pelo autor, destacam-se: a inquirição (debriefing), a terapia narrativa, a terapia cognitivo-comportamental, a psicoterapia e os grupos de autoajuda.

Pensando especificamente no trabalho da terapia cognitivo-comportamental, um dos aspectos abordados por ela é a discussão a respeito das melhores estratégias de enfrentamento (coping). Entendem-se como coping os mecanismos cognitivos e comportamentais, em constante transformação e atualização, mobilizados como processo de gerenciamento de exigências internas e externas que são avaliadas como superiores aos recursos do indivíduo (ZAPF; GROSS, 2001). Essas estratégias podem ser centradas no problema ou centradas na emoção.

De acordo com Niedl (1996), o assédio moral no trabalho é uma situação da qual não se tem controle, assim, estratégias de coping ativas e construtivas não se mostraram úteis e muitas vezes só tornaram a situação pior. Evitar o conflito se mostrou como a única estratégia razoável.

Diversas pesquisas mostraram que mudar de grupo de trabalho ou mesmo de departamento parece ser uma das soluções usadas com sucesso por vítimas e que confrontar abertamente o agressor tende a piorar o problema (ZAPF; GROSS, 2001; RAYNER, 1999; AQUINO; BRADFIELD, 2000).

Os cuidados emocionais visam transmitir aceitação, respeito e compreensão; tranquilização e apoio; encorajar a exposição dos sentimentos; fornecer orientação e garantir um seguimento adequado. É aconselhável que ocorra também um aconselhamento legal para garantir que os direitos de todos os envolvidos no caso sejam interpretados corretamente caso seja tomada alguma ação legal (INTERNATIONAL COUNCIL OF NURSES, 2007). 
Namie e Namie (2000) fazem várias sugestões sobre o que deveria ser contemplado no aconselhamento às vítimas de assédio moral no trabalho, tais como: ajudar a vítima a conseguir apoio; assisti-la a viver o luto pelas perdas decorrentes do assédio (de uma promoção, de um cargo ou de uma carreira, de relacionamentos, da autoconfiança); favorecer a avaliação dos impactos financeiros do assédio (custos advocatícios, com tratamentos de saúde, perdas de dias de trabalho e possível perda do emprego) e realizar um planejamento financeiro para as várias eventualidades; ajudar o paciente a avaliar o que está ocorrendo da perspectiva de quem está fora do problema e a considerar um plano de fuga, como, por exemplo, procurar outro emprego; auxiliar a vítima de assédio a focar habilidades úteis fora do trabalho; ajudar o paciente a buscar um acordo ou uma solução legal.

Para Cassito et al. (2003), um confidente ou ouvidor, interno ou externo à organização, poderia receber a incumbência de ouvir qualquer pessoa que se considere uma vítima de assédio. O próprio reconhecimento do problema da pessoa é essencial para quebrar a negação que frequentemente encobre a agressão. Permite também que a pessoa clarifique sua experiência, distancie-se da situação e tome iniciativas a fim de parar a agressão.

Leymann (2000) considera como obrigação da empresa proteger os indivíduos assediados, evitando que eles sejam estigmatizados ou tenham a sua reputação manchada. Ele considera que deixar o trabalhador passar pelo processo de assédio moral e depois o demitir pode ser classificado como um grande fracasso gerencial.

Para Soares (2006), é essencial planejar bem o programa de retorno ao trabalho de um indivíduo que se afastou em razão do assédio moral ou pelos danos à saúde mental dele decorrentes. É primordial que as fontes de assédio moral e os problemas de saúde mental sejam eliminados para que a pessoa possa retornar às atividades ocupacionais.

A reabilitação está frequentemente centrada na minimização dos sintomas do Transtorno de Estresse Pós Traumático. Entretanto, é necessária uma consideração cuidadosa das circunstâncias individuais, porque nem sempre retornar a vítima ao local de trabalho é a melhor opção (BESWICK; GORE; PALFERMAN, 2006).

O apoio social é considerado uma variável importante que traz um efeito favorável sobre o indivíduo e que amortiza as condições estressantes sobre a saúde mental (KARASEK; THEORELL, 1990).

O estudo de Zapf, Knorz e Kulla (1996), com uma amostra autosselecionada de pessoas assediadas mo- ralmente na Alemanha, concluiu que aqueles que referiram o assédio também referiram baixo apoio social por parte do supervisor e de colegas quando comparados com aqueles que não passaram por assédio moral no trabalho.

Para Cassito et al. (2003), a criação de um grupo de apoio, constituído por pessoas que sofreram assédio moral em diferentes situações, permite o compartilhamento de experiências, a conscientização de que a pessoa não é responsável pelo evento, o reconhecimento da agressão e a modificação de comportamentos.

Para assediadores: coaching, reabilitação, transferência ou desligamento. Os assediadores, assim como as vítimas, podem necessitar de reabilitação (BESWICK; GORE; PALFERMAN, 2006). Segundo Crawshaw (2008), menos atenção tem sido devotada à reabilitação de superiores que assediam seus subordinados (abrasive leaders). Ela descreve um método de coaching planejado especificamente para reabilitar líderes que assediam. O líder é treinado para usar empatia no desenvolvimento de estratégias menos destrutivas de gerenciamento interpessoal. $\mathrm{O}$ comportamento de assediar é compreendido como uma defesa mal adaptativa do supervisor contra ser percebido como inadequado ou incompetente. Qualquer incompetência percebida no subordinado é experimentada como uma ameaça, interpretada de forma errônea como uma resistência intencional do empregado, e o superior se defende contra essa ameaça percebida através de agressão. A reabilitação dos assediadores através do coaching também é sugerida por Vartia et al. (2008).

Glendining (2001) defende que se a situação de assédio continuar, o agressor deve ser transferido para uma posição onde haja menos oportunidade para assediar outros ou mesmo ser demitido.

Para assediados e assediadores: mediação, arbitragem e ouvidoria. As ações de negociação incluem as tentativas de esclarecer com a outra parte as desavenças que produzem o conflito, por vezes apoiando-se em terceiros (representantes do Departamento de Recursos Humanos ou de níveis superiores da hierarquia), buscando conseguir uma arbitragem por parte dos responsáveis pela organização. Os processos de mediação podem dar às partes a oportunidade de construir uma solução "sob medida" para o problema (BARÓN DUQUE, 2002). Esta estratégia pode fornecer ótimos resultados se aplicada no início dos conflitos, antes de se configurar uma situação grave e crônica.

A negociação é um processo simples de regatear e buscar acordo através de concessões recíprocas (BELLENGER, 1984). É um processo de troca que se desenvolve entre as diversas partes (duas pelo 
menos), chamadas de protagonistas. Esses protagonistas podem representar interesses próprios ou de algum grupo na qualidade de porta-vozes.

No assédio moral no trabalho, é difícil que o assediador se identifique como uma das partes do conflito, dado que o anonimato é uma de suas melhores ferramentas, principalmente quando o conflito está muito avançado. Ao mesmo tempo, a desorientação inicial do assediado facilita que o processo avance sem que a negociação seja utilizada (BARÓN DUQUE, 2002). Entretanto, a negociação, oficialmente instituída, pode impedir o avanço do conflito. De preferência, isto deveria ocorrer no início do processo, visto que a mediação só será eficaz nas primeiras etapas de evolução do assédio moral no trabalho (BARÓN DUQUE; MUNDUATE JACA; BLANCO BAREA, 2003).

Segundo Cassito et al. (2003), um mediador poderia oferecer às pessoas envolvidas no conflito a oportunidade de se compreenderem, analisarem o ocorrido e negociarem uma solução. Ainda em segundo estes autores, a mediação representa uma nova oportunidade outorgada aos protagonistas de tentar resolver os problemas que provocam a falta de acordo. Pode ser conveniente a assessoria de serviços ou de profissionais de mediação inclusive durante o processo de negociação.

É necessária uma mudança cultural para a incorporação da mediação nas disputas laborais (GOTTHEIL; SCHIFFRIN, 1996) cuja base essencial se assente em três aspectos: na vontade das partes de incorporar-se em uma nova dinâmica negociadora com a concorrência de uma terceira parte neutra; no abandono das soluções impostas por terceiros (por exemplo, as vias judiciais); e no abandono da crença de que as partes não são capazes de resolver os conflitos que a sua relação organizacional provoca (BARÓN DUQUE, 2002).

Os serviços de saúde ocupacional podem também ser envolvidos na análise da situação do paciente em um papel de mediador (VARTIA et al., 2003).

\section{Intervenções de nível 2: para grupo, equipe e colegas de trabalho (interface indivíduo $x$ organização)}

A European Agency for Safety and Health at Work (2002a) afirma que no nível da interface do indivíduo com a organização deveria ser buscada a melhoria dos relacionamentos no trabalho, a melhoria da adequação pessoa-ambiente ou da autonomia. Para Van der Hek e Plomp (1997), no nível da interface indivíduo x organização, as intervenções dirigem-se a uma melhor adequação pessoa-ambiente através do fortalecimento do apoio social e do enriquecimento do trabalho. Os estudos analisados por eles descrevem a criação de grupos de apoio de colegas com o objetivo de promover o relacionamento indivíduo x organização. Os grupos são definidos como redes de pessoas que ocupam cargos similares na organização e consideram-se como tendo necessidades e metas comuns. $\mathrm{Na}$ intervenção descrita, essas pessoas se reuniam para solucionar problemas em comum, apoiavam-se mutuamente e melhoravam suas habilidades. A ênfase primária dos encontros do grupo era: compartilhar os problemas, tranquilizar e dar apoio, trocar estratégias de coping bem-sucedidas e escutar com empatia. O maior problema é a incorporação desses grupos pela organização.

Leymann (1996), Einarsen, Raknes e Matthiesen (1994) afirmam que um caso de assédio moral no trabalho é tipicamente desencadeado por um conflito relacionado ao trabalho. Em alguns casos, o clima social do trabalho se torna mais do que amargo e cria conflitos que podem escalar para conflitos mais personificados (VAN DE VLIERT, 1984) e até "guerras de escritório" (KAYE, 1994). Intervenções que buscam a melhoria do clima psicológico no trabalho são recomendadas e necessárias, especialmente em casos de assédio moral organizacional, isto é, situações nas quais os procedimentos e as práticas organizacionais são percebidos como opressivos, humilhando e degradando os empregados tão frequente e persistentemente que muitos empregados se sentem vitimizados por eles (EINARSEN et al., 2003).

É inegável a necessidade de aconselhamento ou grupos de apoio às testemunhas de situações de assédio moral no trabalho, dado que estas também podem sofrer repercussões na saúde mental (SOARES, 2006).

\section{Intervenções de nível 3: com foco nas organizações}

A negação por parte da organização de que o assédio moral possa existir ou efetivamente exista nela serve apenas para reforçar a natureza silenciosa e invisível desse risco ocupacional (HARTIG; FROSCH, 2006).

Segundo Brodsky (1976), para o assédio moral no trabalho ocorrer, seus elementos devem existir em uma cultura organizacional que permite e até recompensa tais tipos de comportamento. $\mathrm{O}$ assédio moral só ocorre quando o assediador acredita ter o apoio ou pelo menos a permissão implícita dos superiores para assediar. A tolerância organizacional ao assédio moral é comunicada pela ausência de sanções em relação às pessoas que violam normas informais e valores e pela existência e cumprimento de políticas antiassédio moral.

Um agressor potencial, do tipo patológico, que usa a violência intencionalmente, sempre calcula os possíveis efeitos e benefícios a serem ganhos com o comportamento agressivo em contraposição aos possíveis perigos - retaliação, condenação so- 
cial etc. - (BJÖRQVIST; ÖSTERMAN; HJELT-BACK, 1994; BJÖRKQVIST; ÖSTERMAN; LAGERSPETZ, 1994). Embora se reconheça que em alguns casos pode haver um comportamento premeditado, isso nem sempre se verifica, tendo em vista que o assédio moral pode aparecer como uma defesa psíquica (BATISTA, 2008; BRANDT; DAMERGIAN, 2008).

Outro ponto a se considerar é que o assédio moral nem sempre é contraproducente para a empresa. Segundo Zapf e Einarsen (2005), o assédio moral no trabalho é contraproducente para a vítima. A situação é diferente para o assediador e a organização. Do ponto de vista do assediador, muitos casos de assédio moral se encaixam na perspectiva de comportamento micropolítico nas organizações (ver, por exemplo, ZAPF et al., 2003). Alguns assediadores e empresas podem até mesmo beneficiar-se do assédio moral. Da perspectiva da organização, o assédio moral tem sido repetidamente chamado de gerenciamento de recursos humanos por outros meios (LEYMANN, 1993). Em países com um sistema legal e social forte, é quase impossível demitir-se alguém sem o consentimento da pessoa. Se não há meios legais (ou existem altos custos econômicos), pode haver a tentação de se utilizar outros meios, como, por exemplo, o assédio moral até que a pessoa deixe a organização "voluntariamente". Entretanto, muitas vezes existe um cálculo de custo-benefício, ou seja, é provável que a organização deixe de assediar moralmente se o custo for muito alto. Isto, no entanto, pode não ocorrer quando o conflito já escalou muito (LEYMANN, 1993).

\section{a) Estabelecimento de uma política contra assédio moral}

Parece haver um consenso na literatura de que é importante a criação, pelas organizações, de uma política contra o assédio moral (ver, por exemplo, EUROPEAN AGENCY FOR SAFETY AND HEALTH AT WORK, 2002a; EUROPEAN AGENCY FOR SAFETY AND HEALTH AT WORK, 2002b; BESWICK; GORE; PALFERMAN, 2006). São listadas no Quadro 2 as principais recomendações sobre como deve ser esta política, sintetizadas a partir dos estudos levantados.

Quadro 2 Principais recomendações sobre como deve ser a política antiassédio moral sintetizadas a partir dos estudos levantados

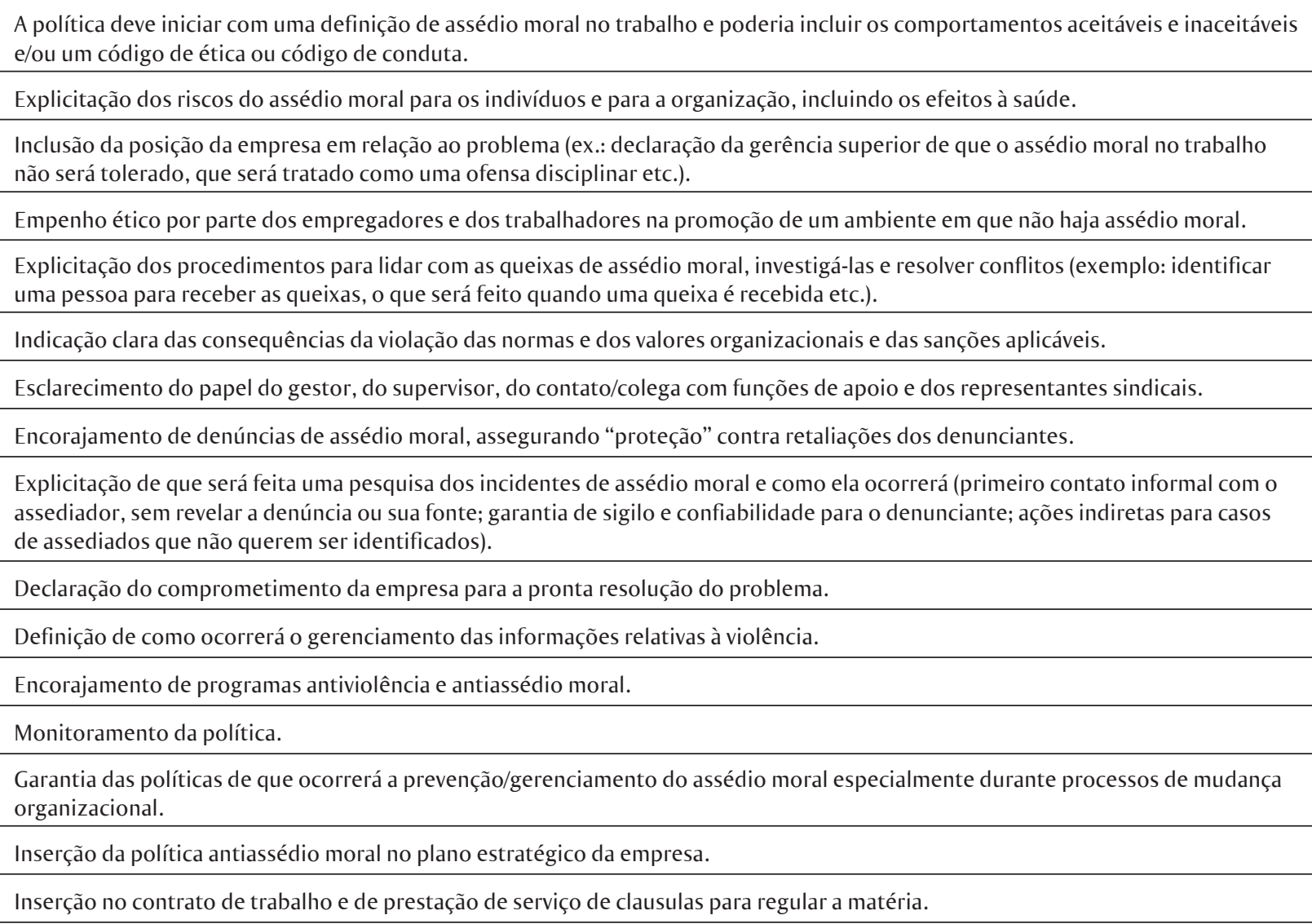

Fontes: European Agency for Safety and Health at Work (2002a, 2002b); Beswick et al. (2006). 


\section{b) Disseminação da política e informações}

Para Beswick, Gore e Palferman (2006) e Soares e Ferreira (2006), a simples existência de um documento estabelecendo uma política antiassédio moral é uma condição necessária, mas não suficiente, para a prevenção do assédio moral no trabalho. É um bom início, mas a menos que esta política seja efetivamente comunicada e colocada em prática, ela não passa de palavras em um pedaço de papel (BESWICK; GORE; PALFERMAN, 2006).

É consenso entre os autores consultados a importância da disseminação da política e de informações sobre o assédio moral no trabalho. O Quadro 3 trata das principais recomendações sobre como deve ocorrer esta disseminação, sintetizadas a partir dos estudos levantados.

\section{c) Mudanças nas situações que caracterizam o assédio moral organizacional no trabalho e que podem favo- recer o assédio moral interpessoal no trabalho}

Vários fatores relacionados ao trabalho têm sido bem documentados como precursores potenciais do assédio moral, entre eles: a carga de trabalho e o clima competitivo (SALIN, 2001); insegurança no cargo (VARTIA, 1996), pressão temporal, alta dependência de cooperação, falta de clareza sobre estruturas de comando, altos níveis de ambiguidade e conflito de papel e baixo controle sobre o trabalho associado a altas demandas (ZAPF; KNORZ; KULLA,1996; ZAPF, 1999; VARTIA, 1996; VARTIA, 2001; HOEL; RAYNER, 1997; EINARSEN; RAKNES; MATTHIESEN, 1994; LEYMANN, 1996; ANDERSSON, 2001); liderança destrutiva, autocrática, não contingente, por conflito, desinteressada e laissez faire (EINARSEN; RAKNES; MATTHIESEN, 1994; O'MOORE et al., 1998; VARTIA, 1996; HOEL; COOPER; FARAGHER, 2001; AASLAND;
SKOGSTAD; EINARSEN, 2008; NIELSEN; MATTHIESEN; EINARSEN, 2005).

Dois tipos de comportamento inadequado que o superior pode adotar frente a uma situação de conflito são: envolver-se de igual para igual, aumentando ainda mais a discórdia; ou negar que o conflito existe. Esses dois comportamentos são muito perigosos e, quando associados a problemas decorrentes da organização do trabalho, são as maiores causas do desenvolvimento do assédio moral no trabalho (ADAMS; BRAY, 1992; KILE, 1990). Cassito et al. (2003) acrescem, aos problemas acima citados, os aspectos da organização do trabalho e a inadequação do ambiente de trabalho.

Alguns dos problemas ligados à organização do trabalho e favorecedores do assédio moral interpessoal no trabalho são: a falta crônica de pessoal, pesados constrangimentos no trabalho, tarefas mal definidas, excesso de hierarquia, instruções insuficientes, métodos de trabalho inadequados e falta de informação (CASSITO et al., 2003; BECKER, 1993; KILE 1990; LEYMANN 1992b; NIEDL, 1996).

Outros autores apontam para a relação entre comportamentos agressivos e mudanças organizacionais, tais como a introdução de uma nova tecnologia, a flexibilização da produção, o downsizing e a reestruturação produtiva, que podem resultar na precarização do trabalho e no medo de perder o emprego (CASSITO et al., 2003; BARON; NEUMAN, 1996; HOEL; COOPER, 2000; MCCARTHY, 1996; SHEEHAN, 1999; HEALTH AND SAFETY AUTHORITY, 2002). A terceirização e a multiplicação de subsidiárias com traços culturais diferentes podem produzir situações que levem à negligência de características humanas e locais dos empregados (CASSITO et al., 2003).

Quadro 3 Principais recomendações sobre como deve ocorrer a disseminação da política antiassédio, sintetizadas a partir dos estudos levantados.

$$
\begin{aligned}
& \text { Disseminação de informações sobre o assédio moral no trabalho, sua prevenção e gerenciamento, em diversas ocasiões e } \\
& \text { de várias formas, direcionadas a todos os integrantes da empresa, inserindo questões conceituais e procedimentos para } \\
& \text { reduzir o risco e para enfrentamento de casos; e contatos dentro da empresa. } \\
& \text { Exemplos: campanhas de sensibilização, newsletter, manuais do trabalhador, encontros da equipe ou da organi- } \\
& \text { zação, comunicação via intranet, e-mail, televisão corporativa, textos em revistas da empresa, palestras e treina- } \\
& \text { mento, boletins informativos etc. }
\end{aligned}
$$

Em respeito aos direitos individuais, não é apropriado incluir exemplos específicos do local de trabalho ou resultados das investigações.

Fornecer informações sobre boas práticas e exemplos positivos.

Os trabalhadores, profissionais do Sesmt, pessoas de contato dentro da empresa, gerentes e supervisores deveriam ser treinados sobre como seguir os procedimentos estabelecidos para reduzir o risco de assédio moral no trabalho.

Fontes: European Agency for Safety and Health at Work (2002a, 2002b); Beswick et al. (2006). 
As principais intervenções no nível organizacional, de acordo com a literatura científica, envolvem rever aspectos da organização do trabalho que favorecem o assédio moral, tais como estrutura hierárquica, critérios de estabelecimento de metas, desenho dos cargos, carga de trabalho, horários de trabalho, conteúdo do trabalho, controle sobre o trabalho, ritmo de trabalho, reconhecimento no trabalho, padrão comunicacional, dimensionamento das equipes e dos métodos de trabalho, definição das funções das empresas, com alto controle e poder de decisão. Deve-se observar também autonomia no trabalho; redução da quantidade de trabalho monótono e repetitivo; aumento da informação sobre os objetivos organizacionais; aumento da clareza na especificação de funções e tarefas.

As práticas de Recursos Humanos, incluindo seleção, treinamento, plano de carreira, avaliação de desempenho, sistemas de remuneração e benefícios, formas de contratação e sua relação com o assédio moral no trabalho devem ser igualmente contempladas.

Além da estrutura organizacional, aspectos ligados ao estilo de liderança são contemplados em uma intervenção organizacional, abordando o desenvolvimento de estilo gerencial mais adequado/ético, a reestruturação do quadro gerencial, o treinamento para gerentes envolvidos nos casos de assédio moral e o treinamento gerencial sobre resolução de conflitos e comunicação. A avaliação dos procedimentos de mudanças organizacionais e a adequação dos programas de saúde corporativa também são estratégias no nível organizacional, conforme relatado na literatura.

Para que as intervenções tornem-se boas práticas, Leka e Cox (2008) sugerem algumas ações. Da mesma forma, são encontrados na literatura científica vários fatores de sucesso em propostas de intervenção em casos de assédio moral (EUROPEAN AGENCY FOR SAFETY AND HEALTH AT WORK, 2002a; PEIRÓ, 2002). O Quadro 4 elenca as boas práticas e os fatores de sucesso de acordo com esses autores. Na comparação entre as listas de boas práticas e de fatores de sucesso, aparecem várias sugestões semelhantes e algumas diferenças também. Em comum, as duas listas abordam a importância do diagnóstico inicial e da revisão da literatura. A partir do diagnóstico, são desenhadas intervenções específicas para cada organização. As duas listas abordam a importância do apoio da hierarquia superior e a necessidade de envolvimento de todos os atores sociais. A necessidade da avaliação sistemática das intervenções e da promoção do reconhecimento do assédio moral aparece apenas nas boas práticas. Nos fatores de sucesso aparecem outras sugestões, tais como: o uso do saber do trabalhador e dos especialistas, a priorização apenas daquilo que efetivamente pode ser modificado e a importância da pressão social para que as mudanças ocorram.

Para Beswick, Gore e Palferman (2006), é necessário priorizar os esforços de pesquisa na avaliação das intervenções e na disseminação das melhores práticas.

Quadro 4 Boas práticas e fatores de sucesso nas intervenções em casos de assédio moral no trabalho segundo os estudos levantados

\begin{tabular}{|l|l|}
\hline \multicolumn{1}{|c|}{ Boas práticas } & \multicolumn{1}{c|}{ Fatores de sucesso } \\
\hline $\begin{array}{l}\text { Embasamento das intervenções nas teorias científicas e no } \\
\text { conhecimento sobre as causas e a natureza de processo cres- } \\
\text { cente (escalating) do assédio moral e da violência. }\end{array}$ & $\begin{array}{l}\text { Intervenções baseadas em evidências e conhecimentos científicos. } \\
\text { Equilíbrio entre as intervenções baseadas em evidências científi- } \\
\text { cas e aquelas baseadas no contexto da organização. }\end{array}$ \\
\hline $\begin{array}{l}\text { A adequada análise da situação e a identificação dos riscos } \\
\text { de assédio moral e violência deveriam constituir a base das } \\
\text { intervenções. }\end{array}$ & $\begin{array}{l}\text { Um planejamento minucioso e um enfoque passo a passo: o } \\
\text { primeiro passo deveria ser uma análise adequada dos riscos } \\
\text { através de diversos meios e dos recursos disponíveis, seguido do } \\
\text { desenvolvimento de intervenções adequadas, de sua implemen- } \\
\text { tação e avaliação. }\end{array}$ \\
\hline $\begin{array}{l}\text { As intervenções deveriam ser planejadas (tailored) para re- } \\
\text { sponder aos problemas e às necessidades específicas de cada } \\
\text { organização e indivíduo. }\end{array}$ & $\begin{array}{l}\text { O nível de apoio e envolvimento da gerência superior: mudanças } \\
\text { não ocorrem a menos que a gerência esteja pronta a mudar e } \\
\text { disposta a investir nas melhorias do local de trabalho. }\end{array}$ \\
\hline $\begin{array}{l}\text { O comprometimento e o apoio da gerência aos objetivos e à } \\
\text { implementação das intervenções são cruciais. }\end{array}$ & $\begin{array}{l}\text { Envolvimento e compromisso dos diferentes atores sociais } \\
\text { (stakeholders): representantes dos trabalhadores, gerência média } \\
\text { e superior, consultores, pesquisadores e outras partes, em cada } \\
\text { estágio do processo. }\end{array}$ \\
\hline $\begin{array}{l}\text { Todas as pessoas envolvidas na intervenção deveriam participar } \\
\text { efetivamente do processo. }\end{array}$
\end{tabular}


continuação $(. .$.

Quadro 4 Boas práticas e fatores de sucesso nas intervenções em casos de assédio moral no trabalho, segundo os estudos levantados

\begin{tabular}{|c|c|}
\hline Boas práticas & Fatores de sucesso \\
\hline $\begin{array}{l}\text { Uma estratégia de avaliação deveria ser desenvolvida, clara- } \\
\text { mente ligada aos objetivos de intervenção delineados, às metas } \\
\text { e aos problemas identificados. }\end{array}$ & - \\
\hline $\begin{array}{l}\text { Uma variedade de métodos deveria ser utilizada para avaliar a } \\
\text { intervenção (por exemplo, inquérito, entrevistas e discussões de } \\
\text { grupos), os quais serão dependentes do tamanho da organi- } \\
\text { zação e dos recursos disponíveis. }\end{array}$ & - \\
\hline $\begin{array}{l}\text { A qualidade e a efetividade do processo de implementação } \\
\text { deveriam ser sistematicamente avaliadas. }\end{array}$ & - \\
\hline $\begin{array}{l}\text { A consciência e o reconhecimento do assédio moral precisam } \\
\text { ser promovidos. }\end{array}$ & - \\
\hline $\begin{array}{l}\text { O assédio moral no trabalho deveria ser visto como um risco } \\
\text { relacionado ao trabalho. A prevenção deveria concentrar-se na } \\
\text { redução dos riscos, dando atenção aos riscos psicossociais, ao } \\
\text { clima organizacional, à cultura organizacional e às práticas de } \\
\text { liderança. As iniciativas que enfocam a personalidade têm meno- } \\
\text { res chances de serem bem-sucedidas. }\end{array}$ & $\begin{array}{l}\text { Uma combinação de medidas dirigidas ao trabalho e medidas } \\
\text { dirigidas ao trabalhador. } \\
\text { Priorizar a prevenção organizacional e coletiva. } \\
\text { Soluções de contexto específico: soluções sustentáveis, especí- } \\
\text { ficas ao local de trabalho, devendo ser desenvolvidas com o uso } \\
\text { de recursos locais. }\end{array}$ \\
\hline- & $\begin{array}{l}\text { A existência de pressões do ambiente social para que as empre- } \\
\text { sas previnam o assédio moral no trabalho. }\end{array}$ \\
\hline- & $\begin{array}{l}\text { Para manter o apoio e a participação, é crucial informar os } \\
\text { trabalhadores tão logo quanto possível dos resultados da análise } \\
\text { de riscos e das atividades planejadas. }\end{array}$ \\
\hline - & $\begin{array}{l}\text { Distinguir condições de trabalho inevitáveis daquelas que po- } \\
\text { dem ser mudadas e não gastar energia com aquilo que não pode } \\
\text { ser modificado. }\end{array}$ \\
\hline- & $\begin{array}{l}\text { Considerar o saber do trabalhador e utilizá-lo para analisar os } \\
\text { problemas e desenvolver as soluções apropriadas. }\end{array}$ \\
\hline- & $\begin{array}{l}\text { Envolver especialistas externos de reconhecido saber e expe- } \\
\text { rientes (pesquisadores, consultores, sindicatos, especialistas } \\
\text { em saúde e segurança no trabalho) e membros da organização } \\
\text { (funcionários e gerentes). }\end{array}$ \\
\hline
\end{tabular}

Fontes: Leka e Cox (2008); European Agency for Safety and Health at Work (2002a); Peiró (2002).

\section{Considerações finais}

Dada a natureza complexa e o caráter multidimensional, relacional e processual do assédio moral no trabalho, fica claro que intervenções pontuais e isoladas não funcionam. É preciso uma abordagem abrangente do problema e um acompanhamento sistemático das ações. As evidências científicas aqui resumidas podem servir como ponto de partida, mas cada caso é um caso e o desenho da intervenção deve considerar o contexto organizacional e envolver os vários atores sociais. Mais do que tudo, é importante uma decisão consciente de fazer as intervenções necessárias e, nesse sentido, o papel da alta gerência é muito importante. Não se pode esquecer, ainda, que o assédio moral no trabalho é fruto de um momento histórico e de um contexto social e econômico definidores da forma de organização do trabalho e do desenho das relações humanas neste contexto. Em última instância, trata-se de uma questão ética e de respeito à dignidade humana. 


\section{Contribuições de autoria}

As duas autoras contribuíram igualmente no projeto, no delineamento, no levantamento de dados, na sua análise e interpretação; na elaboração do manuscrito e na sua revisão crítica; na aprovação final da versão a ser publicada.

\section{Referências}

AASLAND, M. S.; SKOGSTAD, A.; EINARSEN, S. The dark side: defining destructive leadership behaviour. Organizations and People, v. 15, n. 3, p. 20-28, 2008.

ADAMS, A.; BRAY, F. Holding out against workplace harassment and bullying. Personnel Management, v. 24, n. 10, p. 48-52, 1992.

ANDERSSON, J. Informe sobre el acoso moral en el lugar de trabajo. Comisión de empleo y asuntos sociales. [S.l.]: Parlamento Europeo, 2001.

AQUINO, K.; BRADFIELD, M. Perceived victimization in the workplace: the role of situational factors and victim characteristics. Organization Science, v. 11, n. 5, p. 525-537, 2000.

BARON, R. A.; NEUMAN, J. H. Workplace aggression: the iceberg beneath the tip of workplace violence: evidence on its forms, frequency and targets. Public Administration Quarterly, v. 21, n. 4, p. 446-465, 1996.

BARÓN DUQUE, M. Afrontamiento individual del acoso moral en el trabajo a través de los recursos de negociación. Revista de Relaciones Laborales, Harremanak, Universidad del País Vasco, n. 7, p. 135-154, 2002.

BARÓN DUQUE, M.; MUNDUATE JACA, L.; BLANCO BAREA, M. J. La espiral del mobbing. Papeles del Psicólogo, n. 84, p. 55-61, 2003.

BATISTA, J. Violência e assédio moral: patologias da solidão e do silêncio. In: SOBOLL, L. A. P. (Org.) Assédio moral e violência psicológica no trabalho: pesquisas brasileiras. São Paulo: Casa do Psicólogo, 2008.

BECKER, M. Mobbing-ein neues Syndrom [Mobbing - a new syndrome]. Spektrum der Psychiatrie und Nervenheilkunde, v. 22, p. 108-110, 1993.

BELLENGER, R. La negociation. 2. ed. Paris: PUF, 1984. BESWICK, J.; GORE, J.; PALFERMAN, D. Bullying at work: A review of the literature. Health and Safety Laboratory. Working Paper Series, v. 6, n. 4, 2006. Disponível em: <www.hse.gov.uk/research/hsl pdf/2006/hsl0630.pdf>. Acesso em: jun. 2006.

BJÖRQVIST, K.; ÖSTERMAN, K.; HJELT-BACK, M. Aggression among university employees. Aggressive Behaviour, v. 20, n. 3, p. 173-184, 1994.

BJÖRQVIST, K.; ÖSTERMAN, K.; LAGERSPETZ, K. M. J. Sex differences in covert aggression among adults. Aggressive Behavior, v. 20, p. 27-33, 1994.

BRANDT, J.; DAMERGIAN, S. A violência psicológico como uma estratégia quando outros recursos gerenciais fracassam. In: SOBOLL, L. A. P. (Org.) Assédio moral e violência psicológica no trabalho: pesquisas brasileiras. São Paulo: Casa do Psicólogo, 2008.

BRODSKY, C. M. The harassed worker. Lexington, MA: Lexington Books, 1976.

CASSITO, M. G. et al. Raising awareness of psychological harassment at work: advice to health professionals, decision makers, managers, human resources directors, legal community, unions and workers. Geneva: World Health Organization, 2003. (Protecting Workers' Health Series, n. 4).

CHAPPELL, D.; DI MARTINO, V. Violence at work. 3. ed. Geneva: International Labour Office, 2006.

CRAWSHAW, L. Rehabilitating abrasive leaders through executive coaching \& organizational intervention. In: CONFERENCE INTERNATIONALE SUR LE HARCELEMENT PSYCHOLOGIQUE/MORAL AU TRAVAIL, 6. Proceedings... École des Sciences de la Gestion, Université de Québec à Montreál, Montreál, 2008.

DAVENPORT, N.; SWARTZ, R.; ELLIOTT, G. Mobbing: emotional abuse in the American workplace. Ames, IA: Civil Society Publishing, 1999.

DEFRANK, R. S.; COOPER, C. L. Worksite stress management interventions: Their effectiveness and conceptualisation. Journal of Managerial Psychology, v. 2, p. 4-10, 1987.

DI MARTINO, V. Violence at the workplace: the global response. Asian-Pacific Newsletter on Occupational Health and Safety, v. 9, n. 1, p. 4-7, 2002.

DI MARTINO, V.; HOEL, H.; COOPER, C. Preventing violence and harassment in the workplace. Ireland: European Foundation for the Improvement of Living and Working Conditions, 2003.

EINARSEN, S. Harassment and bullying at work: a review of the Scandinavian approach. Aggression and Violent Behavior, v. 5, n. 4, p. 379-401, 2000.

. The nature, causes and consequences of bullying at work: the Norwegian experience. Pistes, v. 7, 2005 [on-line]. Disponível em: <http://www. pistes.uqam.ca/v7n3/articles/v7n3a1en.htm > . Acesso em: 8 fev. 2009.

EINARSEN, S. et al. Bullying and emotional abuse in the workplace: international perspectives in research and practice. London: Taylor and Francis, 2003. 
EINARSEN, S.; MIKKELSEN, E. G. Individual effects of exposure to bullying at work. In: EINARSEN, S. et al. Bullying and emotional abuse in the workplace. London: Taylor and Francis, 2003. p. 127-144.

EINARSEN, S.; RAKNES, B. I. Harrassment at work and victimization of men. In: CONGRESS OF WORK AND ORGANIZATIONAL PSYCHOLOGY, 7., 1995. (Paper presented as a poster)

EINARSEN, S.; RAKNES, B. I.; MATTHIESEN, S. B. Bullying and harassment at work and their relationship to work environment quality: an exploratory study. European Work and Organizational Psychology, v. 4, n. 4, p. 381-401, 1994.

EINARSEN, S.; SKOGSTAD, A. Bullying at work: epidemiological findings in public and private organizations. European Journal of Work and Organizational Psychology, v. 5, n. 2, p. 185-201, 1996. EUROPEAN AGENCY FOR SAFETY AND HEALTH AT WORK. How to tackle psychosocial issues and reduce work-related stress. Systems and Programmes, 2002a. Disponível em: <http://osha.europa.eu/en/ publications/reports/309>. Acesso em: 8 fev. 2009.

. Preventing psychosocial risks at work: European perspectives. Closing event of the European Week for Safety and Health at Work 2002, Bilbao, Spain, 25 November 2002b. Disponível em: <http://osha.europa.eu/en/campaigns/ew2002/ closingprogramme.pdf $>$. Acesso em: mar. 2009.

Prevention of work-related stress in the education sector. E-Facts 31, 2009. Disponível em: $<$ https://osha.europa.eu/en/publications/e-facts/ efact31>. Acesso em: 8 fev. 2009.

FREITAS, M. E.; HELOANI, R.; BARRETO, M. Assédio moral no trabalho. São Paulo: Cengage Learning, 2008.

GLENDINING, P. Workplace bullying: curing the cancer of the American workplace. Public Personnel Management, v. 30, n. 3, p. 269 -288, 2001.

GOTTHEIL, J.; SCHIFFRIN, A. Mediación, una transformación en la cultura. Buenos Aires: Paidos, 1996.

GROEBLINGHOFF, D.; BECKER, M. A case of mobbing and the clinical treatment of mobbing victims.

European Journal of Public Administrations, v. 14, n. 5, p. 845, 1996.

HARTIG, K.; FROSCH, J. Workplace Mobbing Syndrome: the silent and unseen occupational hazard. In: NATIONAL CONFERENCE ON WOMEN AND INDUSTRIAL RELATIONS, 1., 2006, Brisbane. [abstract]. Disponível em: <http://www. mobbingportal.com/absmobbingsyndrome.html>. Acesso em: 10 dez. 2012.

HEALTH AND SAFETY AUTHORITY. Code of practice for employers and employees on the prevention and resolution of bullying at work, 2002. Disponível em: <http://www.hsa.ie/eng>. Acesso em: mar. 2002.
HIRIGOYEN, M. F. Malaise dans le travail: harcèlement moral - démêler le vrai du faux. Paris: Syros, 2001.

. Mal-estar no trabalho: redefinindo o assédio moral. Rio de Janeiro: Bertrand Brasil, 2002.

HOEL. H.; COOPER, C. Destructive conflict and bullying at work. Manchester: University of Manchester Institute Science and Technology, 2000. Disponível em: <http:/www.rowleyassoc.com/wpcontent/uploads/Conflict-Bullying-at-Work.pdf $>$. Acesso em: 10 dez. 2012.

HOEL, H.; COOPER, C.; FARAGHER, B. The experience of bullying in Great Britain: the impact of organizational status. European Journal of Work and Organizational Psychology, v. 10, n. 4, p. 443-465, 2001.

HOEL, H.; RAYNER, C. A summary review of literature relating to workplace bullying. Journal of Community and Applied Social Psychology, v. 7, n. 3, p. 173-256, 1997.

INTERNATIONAL COUNCIL OF NURSES. Guidelines on coping with violence in the workplace. Imprimerie Fornara, 2007. Disponível em: <http://www.icn.ch/>. Acesso em: 8 fev. 2009.

KARASEK, R.; THEORELL, T. Healthy work: stress, productivity and the reconstruction of working life. New York: Basic Book, 1990.

KAYE, K. Workplace wars and how to end them. Turning personal conflicts into productive teamwork. New York, NY: Amacom, 1994.

KILE, S. M. Helsefarleg leiarskap: ein eksplorerande studie [Health-endangering leadership-An exploratory study]. Bergen, Norway: Institutt for Samfunnspsykologi, Universitetet i Bergen, 1990.

LEKA, S.; COX, T. (Ed.). PRIMA-EF: guidance on the European framework for psychosocial risk management: a resource for employers and worker representatives. protecting workers'. Geneva: WHO, 2008. (Health Series, 9)

LEYMANN, H. Mobbing and psychological terror at workplaces. Violence and Victims, v. 5, p. 119-126, 1990.

. Medling och psykosocial rehabilitering

[Mitigation and psychosocial rehabilitation]. Stockholm: Allmänna förlaget, 1991.

. Vuxenmobbning på svenska arbetsplatser. En rikstäckande undersökning med 2.438 intervjuer [Adult mobbing at Swedish workplaces: a nationwide study based on 2,438 interviews.] Stockholm: Arbetarskyddsstyrelsen, 1992a.

. Fran mobbning til utslagning $i$ arbetslivet [From bullying to expulsion from working life]. Stockholm, Sweden: Publica, 1992b.

. The silencing of a skilled technician: mobbing step by step. Working Environment, p. 28-30, 1993. 
. The content and development of mobbing at work. European Journal of Work and Organizational Psychology, v. 5, n. 2, p. 165-184, 1996.

. The Mobbing Encyclopaedia, 2000. Disponível em: <http://www.leymann.se/English/frame.html>. Acesso em: 15 nov. 2009.

LEYMANN, H.; GUSTAFSSON, A. Mobbing at work and the development of post-traumatic stress disorders. European Journal of Work and Organizational Psychology, v. 5, n. 2, p. 251-275, 1996.

MCCARTHY, P. When the mask slips: inappropriate coercion in organisations undergoing restructuring. In: MCCARTHY, P.; SHEEHAN, M.; WILKIE, W. (Ed.). Bullying: from backyard to boardroom. Alexandria, Australia: Millennium Books, 1996. p. 47-65.

MIKKELSEN, E. G.; EINARSEN S. Bullying in danish work-life: prevalence and health correlates. European Journal of Work \& Organizational Psychology, v. 10, n. 4, p. 393-413, 2001.

NAMIE, G.; NAMIE, R. The bully at work: what you can do to stop the hurt and reclaim your dignity on the job. Naperville, Illinois: Sourcebooks Inc., 2000.

NIEDL, K. Mobbing and well-being: economic and personnel development implications. European Journal of Work and Organizational Psychology, v. 5, n. 2, p. 239-249, 1996.

NIELSEN, M. B.; MATTHIESEN, S. B.; EINARSEN, S. Ledelse og personkonflikter: Symtomer på postraumatisk stress blant ofre for mobbing fra ledere [Leadership and bullying. Posttraumatic symptoms among victims after bullying by their leaders]. Nordisk Psykologi, v. 57, n. 4, p. 391-415, 2005.

O'MOORE, M. et al. Victims of workplace bullying in Ireland. Irish Journal of Psychology, v. 19, n. 2-3, p. 345-357, 1998.

PEIRÓ, J. M. Interventions to prevent and correct work-related bullying. 2002. Disponível em: <http:// osha.europa.eu/en/campaigns/ew2002/presentations/ ws2_bullying_interventions_peiro_doc.doc. $>$. Acesso em: 8 fev. 2009.

RAYNER, C. From research to implementation: finding leverage for prevention. International Journal of Manpower, v. 20, n. 1-2, p. 28-36, 1999.

RAYNER, C.; HOEL, H.; COOPER, C. L. Workplace bullying. London: Taylor and Francis, 2002.

RESCH, M.; SCHUBINSKI, M. Mobbing-prevention and management in organizations. European Journal of Work and Organizational Psychology, v. 5, n. 2, p. 295-307, 1996.

SALIN, D. Prevalence and forms of bullying among business professionals: a comparison of two different strategies for measuring bullying. European Journal of Work and Organizational Psychology, v. 10, n. 4, p. 425-441, 2001.
. Ways of explaining workplace bullying: a review of enabling, motivating and precipitating structures and processes in the work environment. Human Relations, v. 56, n. 10, p. 1213-1232, 2003.

SHEEHAN, M. Workplace bullying: responding with some emotional intelligence International Journal of Manpower, v. 20, n. 1-2, p. 57-69, 1999.

. Workplace mobbing: a proactive response.

2004. Trabalho apresentado na Workplace Mobbing Conference, Brisbane, Australia, 14 e 15 out. 2004. Disponível em: < http://www.lindas. internetbasedfamily.com/f/MobMS.pdf $>$. Acesso em: 04 jul. 2009.

SOARES, A. Les bleus à l'âme: le harcèlement psychologique chez les cols bleus de la ville de Montréal. Montreal: Université du Québec à Montréal, 2006a. (Relatorio de pesquisa). Disponível em: < http:// www.angelosoares.uqam.ca/upload/files/Rapports\%20 de\%20recherche/Les_bleus_a_lame_le_harcelement_ chez_les_col_bleus.pdf $>$. Acesso em: 12 dez. 2012.

SOARES, L. Q.; FERREIRA M. C. Pesquisa participante como opção metodológica para a investigação de práticas de assédio moral no trabalho. Revista Psicologia: Organizações e Trabalho, v. 6, n. 2, p. 85-109, 2006.

SOBOLL, L. A. P. Assédio moral no trabalho. In: CATTANI, A. D.; HOLZMANN, L.(Org.). Dicionário Crítico Tecnologia e Trabalho. Porto Alegre: Editora da UFRGS, 2010. p. 40-46.

SPURGEON A. Working time: its impact on safety and health. Seoul: OIT; Occupational Safety and Health Research Institute, 2003.

TEHRANI, N. Counselling and rehabilitating employees involved with bullying. In: EINARSEN, S. et al. Bullying and emotional abuse in the workplace. London: Taylor and Francis, 2003. p. 270-284.

VAEZ, M.; EKBERG, K.; LAFLAMME, L. Abusive events at work among young working adults. Relations Industrielles / Industrial Relations, v. 59, n. 3, p. 569585, 2004.

VAN DE VLIERT, E. Conflict prevention and escalation. In: DRENTH, P. J. D. et al. (Eds.). Handbook of work and organizational psychology. v. 1. Chichester: John Wiley and sons, 1984. p. 521-551.VAN DER HEK, H.; PLOMP, H. N. Occupational stress management programmes: a practical overview of published effect studies. Occupational Medicine, v. 47, n. 3, p. 133-141, 1997.

VARTIA, M. The sources of bullying - psychological work environment and organizational climate. European Journal of Work and Organizational Psychology, v. 5, n. 2, p. 203-214, 1996.

. Bullying at workplaces. In: LEHTINENE,

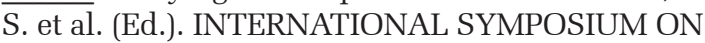
FUTURE TRENDS IN THE CHANGING WORKING 
LIFE. Towards the 21st Century. Proceedings... Helsinki: Institute of Occupational Health, 1991. p. 131-135.

. Consequences of workplace bulling with respect to the well-being of its targets and the observers of bullying. Scandinavian Journal of Work and Environment and Health, v. 27, n. 1, p. 63-69, 2001.

VARTIA, M. et al. Workplace bullying: the role of occupational health services. In: EINARSEN, S. et al. (Ed.). Bullying and emotional abuse in the workplace: international perspectives in research and practice. London: Taylor and Francis, 2003. p. 285-298.

. Rehabilitating abrasive leaders through executive coaching \& organizational intervention. In: CONFERENCE INTERNATIONALE SUR LE HARCELEMENT PSYCHOLOGIQUE / MORAL AU TRAVAIL, 6., Proceedings... Montréal: Université du Québec à Montréal, École des sciences de la gestion, junho 2008. p. 147

ZAPF, D. Organizational work group related and personal causes of mobbing/bullying at work. International Journal of Manpower, v. 20, n. 1-2, p. 70-85, 1999.
ZAPF, D. et al. Empirical findings on bullying in the workplace. In: EINARSEN, S. et al. (Ed.). Bullying and emotional abuse in the workplace: international perspectives in research and practice. London: Taylor and Francis, 2003. p. 103-126.

ZAPF, D.; EINARSEN, S. E. Mobbing at work: escalated conflicts in organizations. In: FOX, S.; SPECTOR, P. E. (Ed.). Counterproductive workplace behaviour: investigations of actors and targets. Washington, DC: American Psychological Association, 2005. p. 237-270.

ZAPF, D.; GROSS, C. Conflict escalation and coping with workplace bullying: a replication and extension. European Journal of Work and Organizational Psychology, v. 10, n. 4, p. 497-522, 2001.

ZAPF, D.; KNORZ, C.; KULLA, M. On the relationship between mobbing factors and job content, social work environment and health outcomes. European Journal of Work and Organizational Psychology, v. 5, n. 2, p. 215-237, 1996. 